\title{
Sex differences and psychological stress: responses to the COVID-19 pandemic in China
}

Shiyan Yan ${ }^{1}$, Rui Xu² ${ }^{2 *}$, Terry D. Stratton ${ }^{3}$, Voyko Kavcic ${ }^{4}$, Dan Luo ${ }^{5}$, Fengsu Hou ${ }^{6}$, Fengying Bi ${ }^{5}$, Rong Jiao ${ }^{7}$, Kangxing Song ${ }^{8^{*}}$ and Yang Jiang ${ }^{3}$

\begin{abstract}
Background: About 83,000 COVID-19 patients were confirmed in China up to May 2020. Amid the welldocumented threats to physical health, the effects of this public health crisis - and the varied efforts to contain its spread - have altered individuals' "normal" daily functioning. These impacts on social, psychological, and emotional well-being remain relatively unexplored - in particular, the ways in which Chinese men and women experience and respond to potential behavioral stressors. Our study investigated sex differences in psychological stress, emotional reactions, and behavioral responses to COVID-19 and related threats among Chinese residents.

Methods: In late February (2020), an anonymous online questionnaire was disseminated via WeChat, a popular social media platform in China. The cross-sectional study utilized a non-probabilistic "snowball" or convenience sampling of residents from various provinces and regions of China. Basic demographic characteristics (e.g., age and gender) - along with residential living arrangements and conditions - were measured along with psychological stress and emotional responses to the COVID-19 pandemic.

Results: Three thousand eighty-eight questionnaires were returned: 1749 females (56.6\%) and 1339 males (43.4\%). The mean stress level,as measured by a visual analog scale, was $3.4(\mathrm{SD}=2.4)$ - but differed significantly by sex. Besides sex, factors positively associated with stress included: age ( $<45$ years), employment (unsteady income, unemployed), risk of infection (exposureto COVID-19, completed medical observation), difficulties encountered (diseases, work/study, financial, mental), and related behaviors (higher desire for COVID-19 knowledge, more time concerning on the COVID-19 outbreak). "Protective" factors included frequent contact with colleagues, calmness of mood comparing with the pre-pandemic, and psychological resilience. Males and females also differed significantly in adapting to current living/working, conditions, responding to run a fever, and needing psychological support services.

(Continued on next page)
\end{abstract}

\footnotetext{
*Correspondence: anxietypsy@163.com; skx301@126.com

${ }^{2}$ Institute of Basic Research in Clinical Medicine, China Academy of Chinese

Medical Sciences, Beijing 100700, China

${ }^{8}$ The First Medical Center, Chinese PLA General Hospital, Beijing 100853,

China

Full list of author information is available at the end of the article
}

(C) The Author(s). 2021 Open Access This article is licensed under a Creative Commons Attribution 4.0 International License, which permits use, sharing, adaptation, distribution and reproduction in any medium or format, as long as you give appropriate credit to the original author(s) and the source, provide a link to the Creative Commons licence, and indicate if changes were made. The images or other third party material in this article are included in the article's Creative Commons licence, unless indicated otherwise in a credit line to the material. If material is not included in the article's Creative Commons licence and your intended use is not permitted by statutory regulation or exceeds the permitted use, you will need to obtain permission directly from the copyright holder. To view a copy of this licence, visit http://creativecommons.org/licenses/by/4.0/ The Creative Commons Public Domain Dedication waiver (http://creativecommons.org/publicdomain/zero/1.0/) applies to the data made available in this article, unless otherwise stated in a credit line to the data. 
(Continued from previous page)

Conclusions: The self-reported stress of Chinese residents related to the COVID-19 pandemic was significantly related to sex, age, employment, resilience and coping styles. Future responses to such public health threats may wish to provide sex- and/or age-appropriate supports for psychological health and emotional well-being to those at greatest risk of experiencing stress.

Keywords: COVID-19, Psychological stress, Sex differences, Psychological resilience

\section{Background}

Novel coronavirus disease 2019 (COVID-19) is now classified by the World Health Organization (WHO) as a full-blown pandemic. In China, where roughly 83,000 cases were confirmed in May 2020, a series of strict control measures were adopted which altered individuals""normal" daily functioning [1]. Publicly, lack of an effective therapy, extended viral latency, asymptomatic infection, and talk of "post-recovery" reinfections exacerbated an already tense and uncertain situation [2-4]. Meanwhile, efforts to contain the spread, such as city lockdowns, home quarantines, and suspension of public and private services, resulted in behavior changes threatening individuals' social, psychological, and economic well-being [5].

As "ground zero" for the pandemic, the COVID-19 threat is feared to have exacted a particularly dramatic psychological toll on the Chinese population. Indeed, a Hong Kong survey conducted during the early phases of the pandemic indicated that $97 \%$ of respondents were worried about COVID-19 - and 99\% were alert to the disease progression, associated anxiety, and perceived susceptibility and severity [6]. Similarly, medical workers reported increased stress, anxiety, and depressive symptoms associated with the emergence, spread, and potential lethality of the virus $[7,8]$.

The potential impact of stress on anxiety, depression, and other neuropsychiatric disorders is well-documented $[9,10]$ - often, following disasters, resulting in posttraumatic stress disorder (PTSD) and substance use disorders [11]. Moreover, since the same preventive measures meant to limit the spread of an infection can paradoxically also heighten risks due to increased social conflict, isolation, devaluation, rejection, and exclusion, such efforts may be somewhat counterproductive [12]. These effects of increased, sustained psychological stress on individuals who, for various reasons, may be differentially impacted should not be discounted.

Sex is one such factor for concern. Clear sex differences have been shown to exist in exposure to potentially traumatic events and subsequent PTSD [13], and other studies have found females to be more vulnerable to developing mental or physical problems in response to life stressors or potentially traumatic events [14-16]. While early research has suggested that female medical workers may experience or respond more negatively to COVID-19-related events [8], the impact on psychological stress affected has not been fully investigated. This study, then, explores the psychological health and well-being of the general population in China, as well as factors - notably, sex - which may moderate its negative impact.

\section{Methods}

In February of 2020, we administered to the general Chinese population an anonymous, online questionnaire using WeChat, a popular social networking platform. The cross-sectional study utilized a non-random "convenience" or "snowball" sample designed to elicit maximum participation by consenting adults. The study protocol received the appropriate human subjects review and approval.

The survey instrument was designed by several coauthors with psychiatric and epidemiological backgrounds (DL, KS, SY) and, in addition to basic information (e.g., sex, age, marital status, living conditions), asked about individuals' experiences (e.g., the current pandemic status of COVID-19 in your area, who do you contact more than 3 times a week, desire to acquire knowledge of COVID-19, how much time concerning on the outbreak, and difficulty encountered during the pandemic, etc.) of and reactions to the COVID-19 pandemic - including psychological stress, resilience, and the perceived need for psychological support services (see Appendix). Psychological stress was measured using a $10-\mathrm{cm}$ visual analogue scale (VAS) anchored at each end with "not stressful" (0) and "extremely stressful" (10, 17]. The Chinese version of the Connor-Davidson Resilience Scale (CD-RISC) was used to assess psychological resilience using 10 items ranging from 0 ("Not at All") to 4 ("Extremely True"). For all measures, higher scores indicated higher levels of the respective construct [17].

\section{Statistical analysis}

All analyses were based on 3088 participants, and descriptive statistics included univariate frequenciesand proportions. Multiple linear regression was used to analyze the influence of various independent variables on self-reported psychological stress, including: sex, age $(<45, \geq 45$ years $)[18,19]$, education, occupation, 
pandemic intensity (provincial prevalence of infections on $03 / 01 / 20)$, existing health conditions $(0,1-2,>2)$, local pandemic status (on the rise, at the peak, steady, uncertainty), respondent's infection status (confirmed, suspected, etc.), household size, frequency of personal contact, COVID-19 related health information needs, and emotional/mood responses. Marital status was found to be highly associated with household size, and thus was excluded from the model.

To explore sex differences, separate stepwise regression models were specified for males and females, with independent $\mathrm{t}$-tests used to assess differences in mean psychological stress and CD-RISC scores. Differences in other measures, such as adaption to current living/working status, coping strategies for running a fever, and the perceived need for psychological support services were analyzed using Chi-square tests.

The specified critical $p$ value for all inferential analyses was $<0.05$, and all analyses were conducted using Statistical Analysis Software 9.4.3 (SAS institute Inc., Cary, NC).

\section{Results}

A total of 3088 questionnaires were returned from residents across 32 Chinese provinces. Respectively, females and males comprised 56.5 and $43.5 \%$ of respondents; the average age was 37.5 years $(\mathrm{SD}=13.5)$. Almost 1 in 5 (18.5\%) were employed as medical personnel $-7.0 \%$ of whom reported working on the "front line" of the pandemic. The characteristics of participants are shown in Table 1. Item descriptions are shown in Table 1 of Appendix. The mean self-reported psychological stress score was 3.4 $(\mathrm{SD}=2.4)$. The Cronbach's alpha of $\mathrm{CD}$ RISC was 0.913 . The average psychological resilience score was $28.6(\mathrm{SD}=8.1)$ (Table 2).

Results of the multiple regression analysis, using psychological stress as the dependent variable, found several statistically-significant predictors, including being: (1) female; (2) < 45 years old; (3) more highly educated; (4) a farmer/worker/clerical and business/service; (5) unemployed; and (6) in poorer health. Having close contact or completing a medical observation, and a desire for know more about COVID-19 were also positively associated with self-reported stress. Variables significantly negatively related to psychological stress included: (1) frequent contact with colleagues; (2) calmness of mood comparing with the pre-pandemic; and (3) psychological resilience (Table 3).

\section{Male and female stressors}

Except for age, high education, and resilience, for male, unstable income population (farmer/worker/clerical and business/service), more time concerning on the COVID19 outbreak, risk infection (close contact or completed a medical observation), psychological and economic problems aggravated psychological stress. In female, poorer health, worse local pandemic status, higher desire for knowledge about the COVID-19, problem of diseases during the pandemic and unable to work/study were the risk factors. Calmness of mood comparing with the prepandemic and frequently contacting with colleagues were protective factors of stress (Table 3 ).

Sex differences did exist with regard to adaptation, responses to potential symptoms, and the perceived need for psychological support services - with males being less adaptive and less likely to see a need for psychological support, but more likely to seek immediate medical attention for suspected feverish symptoms (see Table 2).

\section{Discussion}

Research has consistently shown that major life changes can lead to severe and sometimes chronic psychological stress [20]. With more than 2.1 million cases confirmed worldwide, and over 140,000 reported deaths at the time of this study [21], the COVID-19 pandemic constitutes a pervasive source of potential stress on a global scale. Indeed, with many countries swiftly instituting strict control measures, normal routines were drastically disrupted with the closing of businesses, industries, and schools - and the recommendation (or requirement) that individuals remain at home. Such behavioral changes, whether mandatory or not, can be expected to negatively impact individuals' mental health and/or emotional well-being.

Our study, conducted across provincial China (Taiwan excepted) at the height of the COVID-19 pandemic, suggests that being female, somewhat younger $(<45$ years old), more highly educated, unemployed, and in poorer overall health were all risk factors for experiencing psychological stress. Uncertainty of one's local state pandemic status and some prior personal COVID-19-related contact were also factors contributing to one's perceived stress. In contrast, "protective" factors included frequent contacting with colleagues, calmness of mood comparing with the pre-pandemic, and psychological resilience. A desire for knowledge about COVID-19 and being unable to go to work/study were additional risk factors for stress. The results consistent with similar COVID-19 worldwide studies [22-26].

Disease susceptibility, and the economic problems that can result from an inability to work, can be prime contributors to psychological stress [27, 28]. Similarly, uncertainty and lack of control resulting from lockdowns, restrictions, quarantines, etc. arguably impacted every Chinese residents' life and, potentially, their physical, social-psychological, and economic well-being $[2,3]$. The sustained, long-term implementation of these safeguards undoubtedly prolonged an already stressful and 
Table 1 The demographic information of the respondents $(n=3088)$

\begin{tabular}{|c|c|c|}
\hline Variables & Frequency(n) & Proportions(\%) \\
\hline \multicolumn{3}{|l|}{ Gender } \\
\hline Male & 1339 & 43.4 \\
\hline Female & 1749 & 56.6 \\
\hline Age (years) Mean, SD & $37.5(13.5)$ & \\
\hline$<45$ & 2091 & 67.8 \\
\hline$\geq 45$ & 997 & 32.2 \\
\hline \multicolumn{3}{|l|}{ Marital status } \\
\hline Single & 978 & 31.7 \\
\hline Married & 2014 & 65.2 \\
\hline Divorced & 70 & 2.3 \\
\hline Widowed & 26 & 0.8 \\
\hline \multicolumn{3}{|l|}{ Education } \\
\hline Senior high school/technical secondary school and below & 635 & 20.6 \\
\hline Associate degree in college & 551 & 17.8 \\
\hline Bachelor's degree & 1448 & 46.9 \\
\hline Master's degree and upper & 454 & 14.7 \\
\hline \multicolumn{3}{|l|}{ Employment } \\
\hline Front-line medical personnel & 216 & 7.0 \\
\hline Non-front-line medical personnel & 354 & 11.5 \\
\hline Military & 107 & 3.5 \\
\hline Farmer & 97 & 3.1 \\
\hline Worker & 199 & 6.4 \\
\hline Government and management & 373 & 12.1 \\
\hline Scientist & 96 & 3.1 \\
\hline Teacher & 299 & 9.7 \\
\hline Clerical and business & 92 & 3.0 \\
\hline Service & 320 & 10.4 \\
\hline Student & 582 & 18.9 \\
\hline Unemployed & 98 & 3.2 \\
\hline Others & 423 & 13.7 \\
\hline \multicolumn{3}{|l|}{ Disease self-reported } \\
\hline Without disease & 2440 & 79.0 \\
\hline Respiratory disease & 72 & 2.3 \\
\hline Infectious disease & 17 & 0.6 \\
\hline Cardia-cerebrovascular disease & 199 & 6.4 \\
\hline Disease of digestive tract & 181 & 5.9 \\
\hline Endocrine disease & 93 & 3.0 \\
\hline Urinary system diseases & 51 & 1.7 \\
\hline Malignancy, anemia and other blood diseases & 29 & 0.9 \\
\hline Surgical illness & 71 & 2.3 \\
\hline Mental disorder & 10 & 0.3 \\
\hline Others & 140 & 4.5 \\
\hline \multicolumn{3}{|l|}{ Number of diseases self-reported } \\
\hline 0 & 2374 & 76.9 \\
\hline $1-2$ & 694 & 22.5 \\
\hline$\geq 3$ & 19 & 0.6 \\
\hline
\end{tabular}


Table 2 Sex difference on psychology, behaviors and needs to cope with COVID-19

\begin{tabular}{|c|c|c|c|c|}
\hline \multirow[t]{2}{*}{ Variables } & \multirow{2}{*}{$\begin{array}{l}\text { All } \\
\text { respondents }\end{array}$} & \multicolumn{3}{|l|}{ Sex } \\
\hline & & Male & Female & $P$ \\
\hline Psychological stress, mean (SD) & $3.4(2.4)$ & $3.6(2.6)$ & $4.0(2.6)$ & 0.0001 \\
\hline CD-RISC ${ }^{a}$, mean (SD) & $28.6(8.1)$ & $29.6(8.5)$ & $27.8(7.7)$ & $<0.0001$ \\
\hline \multicolumn{5}{|l|}{ Adaption to current status n(\%) } \\
\hline Very adaptable & $260(8.4 \%)$ & $106(7.9 \%)$ & $154(8.8 \%)$ & \multirow[t]{4}{*}{0.0029} \\
\hline Able to adaptable & $1503(48.7 \%)$ & $627(46.8 \%)$ & $876(50.1 \%)$ & \\
\hline Tolerated inadaptable & $746(24.2 \%)$ & $315(23.5 \%)$ & $431(24.6 \%)$ & \\
\hline Inadaptable at most time & $579(18.8 \%)$ & $291(21.7 \%)$ & $288(16.5 \%)$ & \\
\hline \multicolumn{5}{|l|}{ Coping strategy for running a fever n(\%) } \\
\hline Indecision & $66(2.1 \%)$ & $37(2.8 \%)$ & $30(1.7 \%)$ & \multirow[t]{5}{*}{$<0.0001$} \\
\hline Go to fever clinic immediately & $1698(55.0 \%)$ & $783(58.5 \%)$ & $915(52.3 \%)$ & \\
\hline Observe symptoms at home & $1205(39.0 \%)$ & $460(34.4 \%)$ & $745(42.6 \%)$ & \\
\hline Recover by yourself & $52(1.7 \%)$ & $32(2.4 \%)$ & $20(1.1 \%)$ & \\
\hline Others & $67(2.2 \%)$ & $27(2.0 \%)$ & $39(2.2 \%)$ & \\
\hline \multicolumn{5}{|l|}{ Psychological support service needed } \\
\hline Not needed & $503(16.3 \%)$ & $240(17.9 \%)$ & $263(15.1 \%)$ & \multirow[t]{8}{*}{0.0487} \\
\hline Telephone hotline & $53(1.7 \%)$ & $27(2.0 \%)$ & $26(1.5 \%)$ & \\
\hline On line counseling & $175(5.7 \%)$ & $84(6.3 \%)$ & $91(5.2 \%)$ & \\
\hline Self-adjustment methods & $1265(41.0 \%)$ & $528(39.4 \%)$ & $737(42.2 \%)$ & \\
\hline Self-protection and precaution methods & $673(21.8 \%)$ & $287(21.4 \%)$ & $387(22.1 \%)$ & \\
\hline Assessment of mental state & $351(11.4 \%)$ & $138(10.3 \%)$ & $213(12.2 \%)$ & \\
\hline Others & $67(2.2 \%)$ & $35(2.6 \%)$ & $32(1.8 \%)$ & \\
\hline Total & 3088 & 1339 & 1749 & \\
\hline
\end{tabular}

Notes: ${ }^{a}$ CD-RISC Connor-Davidson Resilience Scale for abbreviation, assessing the psychological resilience

challenging situation - and the loss of both income and personal identity associated with the lack of employment likely resulted in increased anxiety. Indeed, for respondents without sustainable incomes, the effects were especially dire.

The full range of possible impacts should be considered when implementing disease control and prevention measures, and disseminating understandable diseaserelated information and providing alternative venues for personal contact with friends or colleagues couldbe effective buffers of psychological stress. Conforming to common perceptions, people alerted to COVID-related risks and threats instinctively seek outside help, confirmed in a recent Chinese study demonstrating that individuals, on average, spent $\geq 3 \mathrm{~h}$ per day during the pandemic associated with mental health [29]. Social support, typically associated with lower depression and anxiety, could further buffer the cognitive effects of stress [30]. Our findings suggest that appropriate social supports (e.g., frequent contactwith colleagues) to relieve stress during a pandemic might include providing more professional knowledge of protective measures, real-time updates and reports, access to urgent medical services, basic living security measures, and alternative means to interpersonal communication.

Age was another factor related to self-reported stress - with study findings suggesting that younger $(\leq 45)$ respondents experienced greater stress. These results were also consistent with the previous COVID-19 studies of the psychological impacts of disasters [29, 31]. Exactly why this is the case remains somewhat unclear: Perhaps older persons direct more cognitive effort to maintaining positive emotions and avoiding negative ones("positive effects") [32]. Conversely, maybe younger residents face greater social, emotional, and/or economic responsibilities toward their families' health and protection.

Our study also highlighted the importance of resilience as a "protective" factor to psychological stress, often visà-vis a greater sense of adaptability and control over one's external environment. In fact, studies have found that psychological resilience both directly and indirectly protects some individuals against stress-related mental health problems (e.g., PTSD, anxiety, depression) [33, 34]. In our study, males' higher resilience may partially explain their comparatively (vs. females) lower stress levels. 
Table 3 Multiple linear regression for psychological stress and its influence factors

\begin{tabular}{|c|c|c|c|c|c|c|}
\hline \multirow[t]{2}{*}{ Variables } & \multicolumn{2}{|c|}{ All respondents } & \multicolumn{2}{|l|}{ Male } & \multicolumn{2}{|l|}{ Female } \\
\hline & Estimates & $P$ values & Estimates & $P$ values & Estimates & $P$ values \\
\hline Intercept & 7.4 & $<.0001$ & 6.9 & $<.0001$ & 9.4 & $<.0001$ \\
\hline sex & 0.3 & 0.0036 & - & - & - & - \\
\hline Age $(<45, \geq 45$ years $)$ & -0.4 & $<.0001$ & -0.4 & 0.0078 & -0.4 & 0.0009 \\
\hline Education & 0.2 & $<.0001$ & 0.3 & $<.0001$ & - & - \\
\hline \multicolumn{7}{|l|}{ Employment (Military as reference) } \\
\hline Unsteady income $e^{a}$ & 0.4 & 0.0002 & 0.4 & 0.007 & - & - \\
\hline Unemployed & 0.6 & 0.0211 & - & - & - & - \\
\hline Number of diseases self-reported & 0.3 & 0.0041 & - & - & 0.4 & 0.0077 \\
\hline Local epidemic status & - & - & - & - & -0.3 & 0.0059 \\
\hline Risk level of the population ${ }^{b}$ & -0.9 & 0.0038 & -1.2 & 0.0057 & - & - \\
\hline Contacted more than 3 times a week with colleagues & 0.3 & 0.0013 & - & - & 0.4 & 0.0007 \\
\hline Desire to acquire knowledge of COVID-19 & -0.2 & 0.0006 & - & - & -0.3 & $<.0001$ \\
\hline Time spent on the outbreak in one day & 0.1 & 0.0396 & 0.2 & 0.007 & - & - \\
\hline Mood changes comparing with the early epidemic phase & -0.4 & $<.0001$ & -0.4 & $<.0001$ & -0.4 & $<.0001$ \\
\hline \multicolumn{7}{|l|}{ Difficulties encountered (Social limitations as reference) } \\
\hline Diseases problems & 0.5 & 0.0235 & - & - & 0.8 & 0.0086 \\
\hline Psychological problems & 1.2 & $<.0001$ & 1.1 & 0.0002 & 1.3 & $<.0001$ \\
\hline Economic problems & 0.8 & $<.0001$ & 0.8 & 0.0004 & 0.9 & $<.0001$ \\
\hline Unable to work/study & 0.3 & 0.0072 & - & - & 0.3 & 0.0357 \\
\hline CD-RISC & -0.1 & $<.0001$ & -0.1 & $<.0001$ & -0.1 & $<.0001$ \\
\hline
\end{tabular}

Notes: ${ }^{a}$ Unsteady income were including farmer, worker, clerical, business and service; ${ }^{\mathrm{b}}$ Close contact or completed a medical observation vs. general people

That female's stress was greater than that of males was also consistent with existing evidence $[14,16]$ and similar studies conducted during the pandemic of COVID-19 from different countries [22-25]. The finding correspondents to epidimeological research suggesting that females have a higher risk of psychological outcomes [35]. Some researchers have hypothezied that higher psychological stress in females may be partially due to their work being more heavily impacted by COVID-19 and the care burden in home $[22,25]$. Observed sex differences regarding stress are also often attributed to differential impacts on individuals' social environmental, psychodynamic, and cognitive processes $[36,37]$. Behavioral responses to distress and the experience/expression of emotion are also thought to be moderated by sex [13] and, more recently, sex differences in susceptibility to stress have been expanded to include physiological factors [38, 39] such as ovarian hormone fluctuations $[36,40]$ and endogenous estradiol changes across the menstrual cycle [41]. Similarly, stress-related fMRI studies have found brain function associated with emotion and stress regulation, selfreferential processing, and cognitive control to be more pronounced in males [42]. Sex differences in self-reported stress are further reflected in the perceived need of psychological support services, which are often most evident in females. The sex differences of stress should be paid attention, and the government should provide appropriated paychological support services to improve female's resilience and alleviate their distress [23].

This study had several limitations. First, although study respondents reflect a national sample, much of the non-random, convenience sample was located outside the heaviest pandemic area. Moreover, the crosssectional design makes establishing the causal nature of relationships problematic. Second, in response to the then-rising COVID-19 pandemic, our use of the WeChat platform may have had some systematic effect on participation. Finally, for ethical reasons, we did not ask about confirmed or suspected infection among respondents; however, the proportion reporting close contact with an infected individual and/or having confirmed medical tests for the virus was quite small.

\section{Conclusion}

Self-reported stress, as measured, was significantly related to sex, age, education, and employment during the pandemic of COVID-19. Findings suggest responses to future emergency situations (e.g., disease pandemics) should bolster appropriate control measures with targeted means of psychological support. 


\section{Supplementary Information}

The online version contains supplementary material available at https://doi. org/10.1186/s12889-020-10085-w.

Additional file 1: Appendix Table 1: Description of pandemic and living status characteristics related to COVID-19. Description of data: Table 1 showed the pandemic and living status information of the participants during the COVID-19 pandemic. Questionnaire: The Questionnaire of the Public Psychological Status during the COVID-19 pandemic period. Description of data: It provided the questionnaire used in our study.

\section{Abbreviations}

WHO: World health Organization; PTSD: Post-traumatic stress disorder VAS: Visual analogue scale; CD-RISC: Connor-davidson resilience scale

\section{Acknowledgements}

Not applicable.

\section{Authors' contributions}

$\mathrm{SY}, \mathrm{KS}, \mathrm{DL}$, and $\mathrm{FH}$ designed the study. KS, DL, and FH wrote the study protocol. QW, FeH, FB, DL, RJ and KS collected the data. SY carried out the analysis with support from TS, VK and YJ. RX and SY wrote the draft of the manuscript. TS, VK and YJ revised the draft. All authors contributed to the final version. The author (s) read and approved the final manuscript.

\section{Funding}

This study was funded by the National Natural Science Foundation of China (81973713), State Administration of Traditional Chinese Medicine of China Support Project (2017ZX10106001), Logistics Research Project (ALB18J002, BHJ15J003), and Chinese Medical Scientific Development Foundation of Beijing City (JJ2018-101), Project of Institute of Basic Research in Clinical Medicine, China Academy of Chinese Medical Sciences (Z0652, Z0608). The funder had no role in the study design, data collection, data analysis, data interpretation, or writing the manuscript.

\section{Availability of data and materials}

The data and material can be accessed from Kangxing Song, skx301@126. com.

\section{Ethics approval and consent to participate}

The study was approved by the institution review board (IRB) of School of Public Health, Central South University (XYGW-2020-04). The informed consent was waived by the IRB.

\section{Consent for publication}

Not applicable.

\section{Competing interests}

There was no competing interests.

\section{Author details}

${ }^{1}$ School of Acupuncture-Moxibustion and Tuina, Beijing University of Chinese Medicine, Beijing 100029, China. ${ }^{2}$ Institute of Basic Research in Clinical Medicine, China Academy of Chinese Medical Sciences, Beijing 100700, China. ${ }^{3}$ Department of Behavioral Science, College of Medicine, University of Kentucky, Lexington, KY 40536, USA. ${ }^{4}$ Institute of Gerontology, Wayne State University, Detroit, MI 48202, USA. ${ }^{5}$ School of Public Health, Central South University, Changsha 410078, Hunan, China. 'Shenzhen Kangning Hospital, Guangzhou 518020, China. ${ }^{7}$ The First Clinical College, Hainan Meidical University, Haikou 570100, China. ${ }^{8}$ The First Medical Center, Chinese PLA General Hospital, Beijing 100853, China.

Received: 15 July 2020 Accepted: 16 December 2020 Published online: 07 January 2021

\section{References}

1. Huang C, Wang Y, Li X, et al. Clinical features of patients infected with 2019 novel coronavirus in Wuhan, China. Lancet. 2020;395:497-506.
2. Guan WJ, Ni ZY, Hu Y, et al. Clinical characteristics of coronavirus disease 2019 in China. NEJM. 2020:382:1708-20.

3. Bai $Y$, Yao L, Wei T, et al. Presumed asymptomatic carrier transmission of COVID-19. JAMA. 2020;323:1406-7.

4. Peleg O, Mass-Friedman M. Worry about terror among young adults living in ongoing security uncertainty. Int J Psychol. 2013:48:407-21.

5. Taghrir MH, Akbarialiabad H, Ahmadi MM. Efficacy of Mass quarantine as leverage of health system governance during COVID-19 outbreak: a mini policy review. Arch Iran Med. 2020;23:265-7.

6. Kwok KO, Li KK, Chan $\mathrm{HH}$, et al. Community responses during the early phase of the COVID-19 epidemic in Hong Kong: risk perception, information exposure and preventive measures. Emerging Infectious Diseases. 2020; 26(7):1575-79.

7. Siyu C, Xia M, Wen W, et al. Mental health status and coping strategy of medical workers in China during the COVID-19 outbreak. MedRxiv. 2020; 2020.2002.2023.20026872.

8. Zhu Z, Xu S, Wang H, et al. COVID-19 in Wuhan: immediate psychological impact on 5062 health workers. MedRxiv. 2020:24:100443.

9. McCloskey RJ, Pei F. The role of parenting stress in mediating the relationship between neighborhood social cohesion and depression and anxiety among mothers of young children in fragile families. J Community Psychol. 2019;47:869-81.

10. Banjongrewadee M, Wongpakaran N, Wongpakaran T, Pipanmekaporn T, Punjasawadwong $Y$, Mueankwan S. The role of perceived stress and cognitive function on the relationship between neuroticism and depression among the elderly: a structural equation model approach. BMC Psychiatry. 2020;20:25.

11. North CS, Pfefferbaum B. Mental health response to community disasters: a systematic review. Jama. 2013;310:507-18.

12. Slavich GM. Social safety theory: a biologically based evolutionary perspective on life stress, health, and behavior. Annu Rev Clin Psycho. 2020; 16:265-95.

13. Street $A E$, Dardis CM. Using a social construction of gender lens to understand gender differences in posttraumatic stress disorder. Clin Psychol Rev. 2018;66:97-105

14. Vigna L, Brunani A, Brugnera A, et al. Determinants of metabolic syndrome in obese workers: gender differences in perceived job-related stress and in psychological characteristics identified using artificial neural networks. Eat Weight Disord. 2019;24:73-81.

15. Yamada M, Sekine M, Tatsuse T. Psychological stress, family environment, and constipation in Japanese children: the Toyama birth cohort study. J Epidemiol. 2019;29:220-6.

16. Ishiguro A, Inoue M, Fisher J, Inoue M, Matsumoto S, Yamaoka K. Genderbased risk and protective factors for psychological distress in the midterm recovery period following the great East Japan earthquake. Disaster Med Public. 2019;13:487-96.

17. Connor KM, Davidson JR. Development of a new resilience scale: the Connor-Davidson resilience scale (CD-RISC). Depress Anxiety. 2003;18:76-82.

18. Yang JH, Zhai ZW, Wu TN. Sociodemographic analysis on health of middleaged intelligentsia. Popul Econ. 2007;05(16):48-52.

19. Pan F, Wang HJ, Wang ZH, et al. Medical cost contributable to hypertension among Chinese middle and old aged residents in 2011. J Hyg Res. 2017; 46(002):246-50.

20. Martinez de Tejada B, Jastrow N, Poncet A, Le Scouezec I, Irion O, Kayser B. Perceived and measured physical activity and mental stress levels in obstetricians. Eur J Obstet Gyn R B. 2013;171:44-8.

21. WHO. Coronavirus disease 2019 (COVID-19) Situation Report - 89. https:// www.who.int/docs/default-source/coronaviruse/situation-reports/20200418sitrep-89-covid-19.pdf; Accessed 18 April 2020. 2020.

22. Xiong J, Lipsitz O, Nasri F, et al. Impact of COVID-19 pandemic on mental health in the general population: a systematic review. J Affect Disord. 2020; 277:55-64.

23. Le XTT, Dang AK, Toweh J, et al. Evaluating the psychological impacts related to COVID-19 of Vietnamese people under the first Nationwide partial lockdown in Vietnam. Front Psychiatry. 2020;11:824.

24. Tee ML, Tee CA, Anlacan JP, et al. Psychological impact of COVID-19 pandemic in the Philippines. J Affect Disord. 2020;277:379-91.

25. Wang C, Chudzicka-Czupała A, Grabowski D, et al. The association between physical and mental health and face mask use during the COVID-19 pandemic: a comparison of two countries with different views and practices. Front Psychiatry. 2020;11:569981. 
26. Wang C, Pan R, Wan X, et al. Immediate psychological responses and associated factors during the initial stage of the 2019 coronavirus disease (COVID-19) epidemic among the general population in China. Int J Environ Res Public Health. 2020;17(5):1729.

27. Cohen S, Tyrrell DAJ. Psychological stress and susceptibility to the common cold. N Engl J Med. 1991;325:606-12.

28. Cohen S, Daj T, Smith AP. Psychological stress in humans and susceptibility to the common cold, clinical disorders and stressful life event. N Engl J Med. 1997;325:217-35.

29. Huang $Y$, Zhao N. Generalized anxiety disorder, depressive symptoms and sleep quality during COVID-19 outbreak in China: a web-based crosssectional survey. Psychiatry Res. 2020;288:112954

30. Shi J, Huang A, Jia Y, Yang X. Perceived stress and social support influence anxiety symptoms of Chinese family caregivers of community-dwelling older adults: a cross-sectional study. Psychogeriatrics. 2020:20(4):377-84.

31. Leung K, Wu JT, Liu D, Leung GM. First-wave COVID-19 transmissibility and severity in China outside Hubei after control measures, and second-wave scenario planning: a modelling impact assessment. Lancet. 2020;395:138293.

32. Jeronimus BF, Snippe E, Emerencia AC, de Jonge P, Bos EH. Acute stress responses after indirect exposure to the MH17 airplane crash. Br J Psycho. 2019:110:790-813

33. Lee EE, Martin AS, Tu X, Palmer BW, Jeste DV. Childhood adversity and schizophrenia: the protective role of resilience in mental and physical health and metabolic markers. J Clin Psychiatry. 2018;79(3):17m11776.

34. Xi Y, Yu H, Yao Y, Peng K, Wang Y, Chen R. Post-traumatic stress disorder and the role of resilience, social support, anxiety and depression after the Jiuzhaigou earthquake: a structural equation model. Asian J Psychiatr. 2020; 49:101958.

35. Lim GY. Prevalence of depression in the community from 30 countries between 1994 and 2014. Sci Rep. 2018;8:2861.

36. Slavich GM, Sacher J. Stress, sex hormones, inflammation, and major depressive disorder: extending social signal transduction theory of depression to account for sex differences in mood disorders. Psychopharmacology. 2019;236:3063-79.

37. Stevens JS, van Rooij SJH, Jovanovic T. Developmental contributors to trauma response: the importance of sensitive periods, early environment, and sex differences. Curr Top Behav Neurosci. 2018;38:1-22.

38. Goldstein JM, Lancaster K, Longenecker JM, et al. Sex differences, hormones, and fMRI stress response circuitry deficits in psychoses. Psychiatry Res. 2015; 232:226-36.

39. King SB, Toufexis DJ, Hammack SE. Pituitary adenylate cyclase activating polypeptide (PACAP), stress, and sex hormones. Stress. 2017;20:465-75.

40. Goldstein JM, Jerram M, Abbs B, Whitfield-Gabrieli S, Makris N. Sex differences in stress response circuitry activation dependent on female hormonal cycle. J Neurosci. 2010;30:431-8.

41. Albert K, Pruessner J, Newhouse P. Estradiol levels modulate brain activity and negative responses to psychosocial stress across the menstrual cycle. Psychoneuroendocrinology. 2015;59:14-24.

42. Kogler L, Seidel EM, Metzler H, et al. Impact of self-esteem and sex on stress reactions. Sci Rep. 2017;7:17210

\section{Publisher's Note}

Springer Nature remains neutral with regard to jurisdictional claims in published maps and institutional affiliations.

Ready to submit your research? Choose BMC and benefit from:

- fast, convenient online submission

- thorough peer review by experienced researchers in your field

- rapid publication on acceptance

- support for research data, including large and complex data types

- gold Open Access which fosters wider collaboration and increased citations

- maximum visibility for your research: over $100 \mathrm{M}$ website views per year

At $\mathrm{BMC}$, research is always in progress.

Learn more biomedcentral.com/submissions 